\title{
Impact of Internal Entrainment on High Intensity Distributed Combustion
}

\begin{abstract}
Colorless Distributed Combustion (CDC) has shown ultra-low emissions and enhanced performance of simulated gas turbine combustors. To achieve distributed combustion, the flowfield must be tailored for desirable mixture preparation within the combustor prior to mixture ignition. Though CDC have been extensively studied using a variety of geometries, heat release intensities, and fuels, the role of internally recirculated hot reactive gases needs to be further investigated and quantified to obtain the minimum requirement of internal entrainment for achieving distributed reaction condition. In this paper, the impact of internal entrainment of product gases on flame structure and behavior is investigated with focus on fostering distributed combustion and to provide guidelines for seeking distributed combustion. To simulate the recirculated gases from within the combustor, a mixture of nitrogen and carbon dioxide is introduced to the air stream prior to mixing with fuel and combustion. Increase in the amounts of nitrogen and carbon dioxide (simulating increased recirculation) increased the reaction volume to occupy larger volume with an overall enhanced and uniform distribution as revealed from the $\mathrm{OH}^{*}$ chemiluminescence intensity. At the same time, the bluish flame is replaced with a more uniform almost invisible bluish flame. The increased recirculation also decreased the NO emission significantly for the same amount of fuel burned. Lowering oxygen concentration from $21 \%$ to $15 \%$ (due to increased recirculation) resulted in $80 \sim 90 \%$ reduction in NO with no impact on CO emission with sub PPM NO emission achieved at an equivalence ratio of 0.7 . The same trend was demonstrated for a range of recirculated gases temperature. The reaction distribution was significantly enhanced with ultra-low emissions for oxygen concentration lower than $16 \%$ setting a minimum recirculation requirement for distributed combustion.
\end{abstract}

Ahmed E.E. Khalil and Ashwani K. Gupta*

Department of Mechanical Engineering, University of Maryland, College Park, MD 20742, USA

Keywords: Colorless distributed combustion, Ultra low $\mathrm{NO}_{\mathrm{x}}$, High intensity distributed combustion, Gas recirculation, High temperature air combustion.

\section{Introduction}

The increased role of natural gas and shale gas in electricity and power generation for energy sustainability have motivated combustion researchers to develop advanced energy conversion

\footnotetext{
* Distinguished University Professor, Corresponding author: Tel.: +1 301405 5276; Fax: +1 301 3149477.

E-mail address: akgupta@umd.edu (A. K. Gupta).
} 
systems that can furnish the current and future energy needs with minimal impact on the environment using these energy sources. These combustion systems need to comply with the increasingly stringent emissions regulation and form a pivotal part of the quest for environmentally friendly energy systems. These combustion systems shall achieve near zero emission of pollutants (such as, $\mathrm{NO}_{\mathrm{x}}, \mathrm{CO}$, unburned hydrocarbons and soot) from the enhanced thermal field uniformity and also prevent local burnout and downtime of the equipment. Colorless distributed combustion (CDC), which shares some of the principles of high temperature air combustion (HiTAC) [1], has been shown to provide the benefits of reducing the emissions of NO and $\mathrm{CO}$, and improved pattern factor (enhanced thermal field uniformity in the entire combustor). Reduced noise and stable combustion have also been shown for CDC conditions. The flames in distributed combustion do not show any visible flame signatures so that the flame so formed is termed colorless due to negligible visible emission as compared to conventional flames.

Colorless distributed combustion (CDC) is focused on high intensity and high performance gas turbine combustors for both stationary and aviation applications. Previous investigations on CDC have shown significant improvement in pattern factor, low noise emission levels and ultralow emissions of NO and $\mathrm{CO}$ [2-5]. Critical requirements to achieve distributed reactions are controlled and rapid mixing between fresh reactants and hot recirculated reactive species from within the combustor to provide spontaneous ignition of the resulting mixture. The distributed reactants results in distributed reaction rate over the entire volume of the combustor rather than the concentrated thin flame front characterized by high reactions rates with local hot spots. The distributed combustion regime not only avoids the formation of thin reaction zone but also the 
hot-spot regions in the flame to mitigate thermal $\mathrm{NO}_{\mathrm{x}}$ emissions produced from the Zeldovich thermal mechanism $[1,6]$.

The importance of good preparation of the air, fuel, and hot recirculated reactive species mixture for ignition cannot be overstated. The role of swirling air injection into the combustion chamber for seeking distributed combustion reactions was explored. The tangential air jet entrains large amounts of product gases from within the combustion chamber. The amounts of entrainment are controlled so as to increase the temperature of the reactant mixture to a level higher than the auto-ignition temperature of the fuel. The uniformly mixed fuel/air/hot active gases then spontaneously ignite to result in a distributed reaction regime, instead of a thin concentrated reaction flame front [3-5]. The mixing of hot reactive gases with the fresh mixture helps to increase temperature of the mixture to cause spontaneous ignition in the entire combustion zone as compared to only small region of the fresh mixture as exhibited in conventional flames for flame stabilization. Ultra-low NO emission along with low CO emission have been demonstrated for swirling CDC combustor [4] under premixed combustion mode, with emission below $5 \mathrm{PPM}$ of NO at a heat release intensity of $27 \mathrm{MW} / \mathrm{m}^{3}$-atm at a rather high equivalence ratio of 0.6 with air preheated to $600 \mathrm{~K}$ to simulate gas turbine combustor inlet temperature conditions. Emissions below 2 PPM have been also demonstrated for normal intake air temperature [3]. Swirling CDC have been investigated using different fuel introduction scenarios [5], fuels [7], and injection velocities [8]. In all cases, ultra-low emissions were demonstrated.

For all these investigations, increased entrainment of recirculated hot reactive gases decreased emissions and enhanced thermal field uniformity in the combustion chamber. However, further investigations are required to determine more precise information on of the amounts of hot 
reactive species required to foster distributed reaction conditions. Increased recirculation of reactive species lowers the mixture oxygen concentration and increases the mixture temperature prior to ignition, and consequently controlling the fate of the reaction distribution. Previous experiments have investigated the conditions (oxygen concentration and temperature) to achieve distributed reactions in furnaces [9], which are characterized by lower thermal intensity and near stoichiometric (richer fuel) combustion as compared to gas turbines. For methane, it was found that oxygen concentration of about $8 \%$ or lower results in a colorless flame. In another investigation, the flame temperature have been measured, showing that the reaction is much more distributed at $4 \%$ oxygen concentration as compared to $21 \%$ oxygen in air. This was demonstrated with and without air preheats prior to combustion [10] with experiments performed at those two oxygen concentration.

Other researchers have investigated the impact of recirculating exhaust gas (exhaust gas recirculation, EGR) on the performance of gas turbine. In one study, $40 \%$ reduction in $\mathrm{NO}_{\mathrm{x}}$ has been demonstrated with $35 \%$ EGR, leading to oxygen concentration of $17 \%$ [11]. In another investigation, it was determined that operation at full load with EGR is an acceptable condition up to $30 \% \mathrm{EGR}$, in the absence of acoustic instabilities and with good combustion efficiency [12].

Obtaining low oxygen concentrations in the mixture prior to ignition can be challenging for gas turbine applications. Gas turbine traditionally run lean, resulting in an oxygen concentration of about $8 \%$ in the products, indicating that large amounts of recirculation will be needed to achieve oxygen concentrations below about $15 \%$. Such large recirculation requirement poses a problem for combustor flowfield design. 
In this paper, the impact of the amount of gas recirculation is investigated with focus on determining the minimum requirements for distributed reactions to occur (hot gas recirculation/oxygen concentration). A swirl burner is used in this investigation with focus on measuring emissions ( $\mathrm{NO}$ and $\mathrm{CO}$ ) and flame behavior for different amounts of recirculation. A mixture of nitrogen and carbon dioxide ( $90 \%-10 \%$ by volume) is used to simulate exhaust gases. Furthermore $\mathrm{OH}^{*}$ chemiluminescence intensity was captured to outline the reaction zone behavior under different operational conditions.

\section{Approach}

Recirculation of hot product gases is the main tool to achieve low oxygen concentration with high temperature environment prior to ignition to control the reaction rate. The global reaction rate for methane air combustion is expressed as a function of temperature (T), methane concentration $\left(\mathrm{CH}_{4}\right)$, and oxygen concentration $\left(\mathrm{O}_{2}\right)[13]$ :

$$
\mathrm{R}=10^{\wedge} \mathrm{A} 1 *\left[\mathrm{CH}_{4}\right]^{\wedge} \mathrm{B} 1 *\left[\mathrm{O}_{2}\right]^{\wedge} \mathrm{C} 1 * \operatorname{Exp}[\mathrm{D} 1 / \mathrm{T}]
$$

where the constants A1 varied between 8.48 and 11.7, B1 varied between -0.3 and $1, \mathrm{C} 1$ varied between 0.8 and 1.3, and D1 varied between -12019 and -24358 , each having the units of kmoles, cubic meters, seconds and Kelvin, respectively. Nicol et al gave a summary of these constants and their values were based on the work of different investigators [13]. Decrease in oxygen concentration, achieved through recirculation of hot reactive species, lowers the reaction rate, which can be countered by higher mixture temperatures, leading to favorable distributed combustion condition. Also, decreasing the oxygen concentration in the mixture increases the ignition delay time [14], allowing for longer mixing time prior to ignition. 
The recirculated gases consist mainly of nitrogen, carbon dioxide, water vapor, and excess oxygen (depending on the stoichiometry of the reaction). To simulate the impact of recirculation of reactive product gases on the combustion process, nitrogen and carbon dioxide are introduced with the fresh mixture, with a focus to determine oxygen concentration at which distributed combustion can be fostered. Based on this required oxygen concentration and the combustor design equivalence ratio, a hot reactive gas recirculation ratio can be determined (taking into account the amount of excess oxygen recirculated).

Nitrogen and carbon dioxide were selected as they form the majority of the product gases. They were mixed in a $90 \% \mathrm{~N}_{2}-10 \% \mathrm{CO}_{2}$ by volume simulating product gases near stoichiometry conditions. Though this ratio changes as the equivalence ratio becomes leaner, the diluting gases mixture (90\%-10\%) was kept constant for all the investigations reported here. This deviation from the actual gases will have minimal impact on the results as nitrogen and carbon dioxide behave similarly in flames. Laminar flame speed and flame temperature for methane-air flames diluted with nitrogen and/or carbon dioxide have shown to exhibit similar behavior $[15,16]$. Diluting the reactants with a nitrogen-carbon dioxide-water vapor mixture also resulted in similar behavior to that of nitrogen [17].

The dilution gases were supplied upstream of the combustor at different temperature to evaluate the role of the mixture temperature prior to ignition on emissions and flame stabilization. Numerical modelling and experiments were performed in order to investigate the impact of the oxygen concentration on distributed combustion and resulting emissions.

\subsection{Numerical}


CHEMKIN-PRO software was used to numerically model the combustion process under different nitrogen-carbon dioxide dilution amounts. GRI 3.0 methane mechanism was employed with a perfectly stirred reactor. The nitrogen-carbon dioxide mixture was mixed with air and fuel prior to introduction to the PSR, leading to change in the oxygen concentration of the reactants. Numerical modeling was also performed using two PSRs, where the product gases of the first PSR were mixed with air and fuel and then introduced to the second PSR. However, this approach led to no change in output temperature and emission regardless of the amount of product gases recirculated, contrary to previous experiments where emissions were reduced significantly with increase in recirculation of hot product gases $[3,8]$.

\subsection{Experimental}

Experiments were performed using a swirl burner with focus on comparing emissions both without and with addition of the nitrogen-carbon dioxide mixture. First, a baseline was established using the swirl burner with no dilution and then nitrogen-carbon dioxide mixture was introduced in different amounts, and noting the emissions and flame behavior. The mixture was preheated to different temperatures, changing the mixture temperature prior to ignition. Details of the experimental facility are given below.

\section{Experimental Facility}

The experiments were performed using a swirl burner fuelled with methane. Details of this swirl burner can be found elsewhere [18]. The performance of this swirl burner has been studied in terms of emissions and velocity profiles using methane and hydrogen enriched methane [1819]. To simulate product gas recirculation and lower oxygen concentration in the mixture prior to 
ignition, different amounts of $\mathrm{N}_{2}-\mathrm{CO}_{2}$ mixture were added to the air upstream of the burner. Fuel was injected at the center of the swirler in a non-premixed configuration.

Air and nitrogen flow rates were controlled by laminar flow controllers with an accuracy of $\pm 0.8 \%$ of reading $\pm 0.2 \%$ of full scale leading to an overall accuracy of about $1.5 \%$ of the reading. Methane and carbon dioxide flow rates were controlled through a gravimetric flow controller with an accuracy of $1.5 \%$ of full scale.

Detailed investigations on the overall emissions from the combustor as well as visible emissions have been performed for the various experimental conditions. The concentration of $\mathrm{NO}$ was measured using a $\mathrm{NO}-\mathrm{NO}_{\mathrm{x}}$ chemiluminescent gas analyzer; $\mathrm{CO}$ concentration was measured using the non-dispersive infrared method and $\mathrm{O}_{2}$ concentration (used to correct the NO and $\mathrm{CO}$ emissions at standard $15 \%$ oxygen concentration) was measured using galvanic cell method. During a single experiment, measurements were repeated at least three times for each configuration and the uncertainty was estimated to be about \pm 0.5 PPM for NO and $\pm 10 \%$ for CO emission. The experiments were repeated at least three times to ensure good repeatability of the experimental data obtained.

For imaging the $\mathrm{OH}^{*}$ chemiluminescent intensity distribution, an ICCD camera coupled to a narrow band filter, centered at wavelength $307 \mathrm{~nm}$ wavelength, was used. A photograph of the experimental test rig is shown in Fig. 1, along with the flame under standard air combustion, where the swirl structure is dominant, and reduced oxygen concentration combustion, showing near distributed combustion with less visible emissions. For both cases, the flames were confined in the quarts tube having an internal diameter of 3 inches and length of 12 inches. The swirl burner details can be found elsewhere [18]. Thermocouples were fitted along the reactor walls to 
confirm the existence of reaction zone at low oxygen concentration as the flame was invisible with almost no combustion noise.

\section{Experimental}

The experimental investigations reported herein were aimed at examining the NO and $\mathrm{CO}$ emission as well as $\mathrm{OH}^{*}$ chemiluminescence intensity as affected by oxygen concentration prior to ignition. Oxygen concentration was varied through supplying different amount of $\mathrm{N}_{2}-\mathrm{CO}_{2}$ mixture (90\%-10\% by volume). First, experiments were performed under various equivalence ratio with different dilution amounts. Afterwards, the heat load was changed (fuel flow rate) along with the burner dimensions to verify that the obtained results hold for different loads/combustor volumes. The $\mathrm{N}_{2}-\mathrm{CO}_{2}$ mixture temperature was then varied to outline the impact of dilution temperature on emissions and flame stability.

Table 1 summarizes the conditions reported here along with the variables manipulated for each case. For each heat load, the fuel flow rate was kept constant while the air flow rate was changed to change the equivalence ratio. For every equivalence ratio, air and fuel flow rates were kept constant while the amount of $\mathrm{N}_{2}-\mathrm{CO}_{2}$ mixture was increased to lower the oxygen concentration in the mixture prior to ignition

\section{Results and Discussion}

\subsection{Numerical Results}

Numerical modelling was performed as an initial investigation, offering guidelines for actual experiments. The PSR was modeled to have the same volume as that of the burner, operating at a heat load of $3.25 \mathrm{~kW}$ and a thermal release intensity of $2.4 \mathrm{MW} / \mathrm{m}^{3}$-atm. Figure 2 shows the 
obtained PSR temperature and NO emission with different dilution amount at an equivalence ratio of 0.9 .

As the oxygen concentration is reduced, through $\mathrm{N}_{2}-\mathrm{CO}_{2}$ dilution, the reactor temperature drops significantly along with $\mathrm{NO}$ emission. This figure suggests that the NO reduction is not only a function of lowering the reactor temperature (with diluents acting as a heat sink), but also the chemical kinetics are affected. For dilution temperature of $1500 \mathrm{~K}$, reducing oxygen concentration from $21 \%$ to $18 \%$ reduced NO emission by about 50\% (750 PPM to 350 PPM) though the PSR temperature was only reduced by $80 \mathrm{~K}$ (2130K to $2050 \mathrm{~K})$. The reduction in NO emission was also plotted against oxygen concentration, see Fig. 3. This plot suggests that significant reduction (about 55\%) can be achieved by reducing oxygen concentration to $18 \%$, with $85 \%$ reduction or higher achieved at oxygen concentration of $14 \%$.

\subsection{Experimental Results}

\subsubsection{Effect of Change in Oxygen Concentration}

The experiments performed at a heat load of $3.25 \mathrm{~kW}$ were with constant fuel flow rate and air flow rate changed to result in different equivalence ratios. Changing the $\mathrm{N}_{2}-\mathrm{CO}_{2}$ mixture amount changed the oxygen concentration in the fresh mixture. Figure 4 shows the NO emission for the different cases.

NO emission decreases significantly with reduction of oxygen concentration in the fresh mixture. NO decreased by some $60 \%$ by reducing the oxygen concentration from $21 \%$ to about 18\%. NO emission lower than 4 PPM was demonstrated regardless of the equivalence ratio as long as the oxygen concentration was lower than 17\%. 2 PPM of NO has been shown even at an equivalence ratio of 0.9 , which is rather high for currently used stationary gas turbines. 
The obtained trend agrees with that obtained through numerical modeling, however, numerical modeling over predicted the reduction in NO. Numerical modeling predicted that NO emissions is reduced by $86.5 \%$ at $\mathrm{T}=300 \mathrm{~K}$ and phi=0.9, the measured value was only about $63 \%$. Also numerical modeling over predicted the NO emission, by an order of magnitude. This overprediction is consistent with results reported earlier for distributed combustion conditions [20]

Figure 5 shows the recorded $\mathrm{CO}$ emissions for the same experimental condition as in figure 4. Decreasing oxygen concentration enhanced the combustion and led to lower $\mathrm{CO}$ emission, especially at the higher equivalence ratios. However, $\mathrm{CO}$ emission increased for each equivalence ratio as the oxygen concentration was further reduced. This increase in $\mathrm{CO}$ emission was associated with lower temperatures and onset of combustion instability and flame blowout near the lean flammability limit.

Figure 6 shows the recorded $\mathrm{OH}^{*}$ chemiluminescence intensity distribution for the different cases. The reduced oxygen concentration, through addition of $\mathrm{N}_{2}-\mathrm{CO}_{2}$ mixture, resulted in less concentrated reaction zone and exhibited lower overall intensity. The structure associated with the swirl burner (as seen for the case of no $\mathrm{N}_{2}-\mathrm{CO}_{2}$ addition) gradually disappeared with oxygen reduction until disappearance at an oxygen concentration of about $14.6 \%$ and lower at an equivalence ratio of 0.9 . The data was also captured at lower equivalence ratio of 0.7 , with similar trend. However, in this case the swirl structure disappeared at a higher oxygen concentration $(16.5 \%)$ compared to the fuel rich case $(14.6 \%)$.

The more distributed nature of the $\mathrm{OH}^{*}$ signal demonstrated with decrease in oxygen concentration in the fresh mixture corresponds well with the recorded data on NO emission shown in Fig. 4. The more distributed the reaction, the lower the NO emission. The $\mathrm{OH}^{*}$ chemiluminescence data suggests that the reaction is rather distributed at lower oxygen 
concentrations (lower than $16 \%$ for phi=0.9 and lower than $17 \%$ for phi $=0.7$ ), indicating that this value (obtained for each equivalence ratio) should be targeted through reactive gases recirculation when designing a combustor flowfield. This value is also supported through NO emission, where minimal NO emission reduction was obtained by lowering the oxygen concentration (lower than $16 \%$ for phi $=0.9$ and lower than $17 \%$ for phi $=0.7$ ).

\subsubsection{Effect of Change in Heat Load and Combustion Volume}

The experiments were also performed at a higher heat load $(5 \mathrm{~kW})$ so as to verify that the results obtained were not configuration specific to a certain heat load and injection velocity. Figure 7 shows the NO emission for the higher heat load at different equivalence ratios and oxygen concentrations along with the equivalent data reported in Fig. 4 for lower heating load.

NO emission decreased significantly with reduction of oxygen concentration in the fresh mixture, similar to that demonstrated at lower heat load. Recorded NO emission for both heat loads are almost identical, indicating that the heat load variation, for the limits investigated herein, has no impact on NO emission. The same comparison was also performed for $\mathrm{CO}$ emission and the results are shown in Fig. 8.

Comparing these $\mathrm{CO}$ emissions with those obtained at the lower heat load, one can see that the values here are higher, especially at equivalence ratio of 0.9 . This increase can be attributed to the reduced residence time in the combustor. As the fuel, air, and dilution mixture flow rates increased to furnish the combustor with appropriate flows for the $5 \mathrm{~kW}$ heating load, the combustor volume was kept constant, leading to a lower residence time inside the combustor. The apparent residence time, obtained by dividing the burner volume by the gases volume flow 
rate, was almost half of that calculated for the lower heating load of $3.25 \mathrm{~kW}$. Such reduced residence time lead to an increase in $\mathrm{CO}$ emission at equivalence ratio of 0.9 .

$\mathrm{OH}^{*}$ Chemiluminescence was also captured for this higher heat load with focus on the flame distribution. As the oxygen concentration was reduced through addition of $\mathrm{N}_{2}-\mathrm{CO}_{2}$ mixture, the reaction becomes less concentrated and exhibit lower overall intensity. Also, the structure associated with the swirl burner (as seen for the case of no $\mathrm{N}_{2}-\mathrm{CO}_{2}$ addition) gradually disappears with oxygen reduction until it disappears at an oxygen concentration of about $15 \%$ and lower for an equivalence ratio of 0.9 , see Fig. 9. The more distributed nature of the $\mathrm{OH}^{*}$ signal demonstrated with decrease in oxygen concentration in the fresh mixture corresponds well with the recorded data on NO emissions shown in Fig. 9 and supports the findings discussed earlier for the lower heat load.

To further investigate the impact of heat release intensity, the combustor volume was also changed, leading to a change in the thermal (heat) release intensity, HRI (defined as the heat load divided by the combustor volume and normalized by the combustor pressure). Since the heat load is a function of the fuel flow rate, the HRI is considered to reflect the apparent residence time available for the fuel to react in a combustor. This value is normalized by the combustor pressure to account for the change in fuel density with change in combustor pressure and this allows a comparison between combustors operating at different pressures. However, in this investigation, experiments were only performed at atmospheric pressure. Change in the HRI affects the apparent residence time to result in lower residence times for higher HRI combustors. Figure 10 shows the NO emission variation with oxygen concentration for four different HRI values. For all the HRI investigated, the NO emission trend was consistent. As the oxygen concentration is reduced, NO emission decreased. A $60 \%$ NO reduction was achieved through 
reducing the oxygen concentration to $18 \%$. As the HRI is increased (up to $5 \mathrm{MW} / \mathrm{m}^{3}$-atm.), NO emissions decreased due to the reduced apparent residence time in the combustor. For the higher HRI of $7.78 \mathrm{MW} / \mathrm{m}^{3}$-atm., the reaction moves further upstream and starts to anchor around the combustor exit leading to a slightly higher $\mathrm{NO}$ emission than that of the $5 \mathrm{MW} / \mathrm{m}^{3}$-atm. case. This trend was consistent for the equivalence ratios examined here as shown in Fig. 10 (solid, phi $=0.9$, dashed, phi=0.7).

Figure 11 shows CO emission variation with HRI and oxygen concentration. As HRI increased, the $\mathrm{CO}$ emission significantly increased due to the reduced apparent residence time so that less time is available for complete $\mathrm{CO}$ to $\mathrm{CO}_{2}$ conversion. This increase was significant, especially at an equivalence ratio of 0.9. At lower equivalence ratio, this increase was less significant. For all HRI examined herein, $\mathrm{CO}$ emission increased at low oxygen concentration due to unstable nature of the flame exhibited at these conditions as further reduction in oxygen concentration led to flame extinction.

\subsubsection{Effect of Dilution Gases Temperature}

The experiments were aimed at identifying the role of dilution gases temperature on emissions. All the previous experiments were aimed at identifying the impact of oxygen concentration reduction (which can be achieved in actual combustion systems through product gas recirculation). However, such recirculation will increase the fresh mixture temperature. In the case of internal recirculation, the product gases recirculated will have temperature of $1500 \mathrm{~K}$ or higher. The $\mathrm{N}_{2}-\mathrm{CO}_{2}$ mixture was preheated to different temperatures with view to understand the impact of diluents temperature on emissions and flame stability. These experiments were 
performed at a heat load of $3.25 \mathrm{~kW}$ and HRI of $2.4 \mathrm{MW} / \mathrm{m}^{3}$-atm. Figure 12 shows the NO emission for different preheat temperature at equivalence ratios of 0.9 and 0.7 .

Increase in the mixture temperature slightly increased the NO emission at a given oxygen concentration. For instance, at phi $=0.9$ and $15.6 \% \mathrm{O}_{2}$, NO emission increased from $2.8 \mathrm{PPM}$ at $\mathrm{T}=300 \mathrm{~K}$, to 3.7PPM for $\mathrm{T}=450 \mathrm{~K}$, and 3.9 PPM at $\mathrm{T}=600 \mathrm{~K}$. NO emissions lower than $2 \mathrm{PPM}$ was demonstrated for oxygen concentration lower than $12 \%$. On the other hand, increasing temperature stabilized the flame at lower oxygen concentration. At $\mathrm{T}=300 \mathrm{~K}$, the burner was stable down to oxygen concentration of $13.8 \%$. When the temperature increased, this limit was increased to lower oxygen concentration of $12.4 \%(450 \mathrm{~K}), 10.8 \%(600 \mathrm{~K})$, and $10.2 \%(750 \mathrm{~K})$.

Similar performance was obtained at leaner equivalence ratio of 0.7 , though the increase of emissions with increase in temperature was much lower (0.6 PPM increase between 300K and $600 \mathrm{~K}$ at $\mathrm{O}_{2}$ concentration of $16.5 \%$ ). Similarly the stable combustion operation was extended to $13.6 \%$ at higher temperature $(750 \mathrm{~K})$ as compared to $16.5 \% \mathrm{O}_{2}$ for $\mathrm{T}=300 \mathrm{~K}$.

The impact of increasing temperature had a significant impact on $\mathrm{CO}$ emission. Higher diluents temperature led to lower $\mathrm{CO}$ emission at equivalence ratio of 0.9 . This is attributed to the higher overall combustion temperature and more energy available for complete $\mathrm{CO}$ to $\mathrm{CO}_{2}$ conversion. For the lower equivalence ratio of $0.7, \mathrm{CO}$ emission did not change much. The change in CO (1 PPM between maximum and minimum point at a given oxygen concentration) at this equivalence ratio is within the range of experimental error and accuracy of the gas analyzer. Figure 13 shows the recorded $\mathrm{CO}$ emissions.

Figure 14 shows the recorded $\mathrm{OH}^{*}$ chemiluminescence intensity distribution for a preheat temperature of $600 \mathrm{~K}$. The reduced oxygen concentration, through addition of $\mathrm{N}_{2}-\mathrm{CO}_{2}$ mixture, resulted in lower overall intensity and a more distributed nature of the flame. The structure 
associated with the swirl burner gradually disappeared with oxygen reduction until disappearance at an oxygen concentration of about $15 \%$ and lower for an equivalence ratio of 0.9 , reiterating the similar findings as that at diluent's temperature of $300 \mathrm{~K}$.

The enhanced distribution with lower oxygen concentration reflected well on the visible emission signatures. As the oxygen concentration was reduced, the flame changed from blue to faint bluish color to almost invisible flame, see Fig. 15, indicating path towards distributed combustion condition.

\subsection{Impact of Dilution}

All of the emission results are reported in PPM. Adding $\mathrm{N}_{2}-\mathrm{CO}_{2}$ mixture to reduce the oxygen concentration will increase the overall flow rate. If the $\mathrm{NO}$ emission remains constant (in terms of mass), its concentration will decrease due to the added diluents, leading to a decrease in NO emission. This apparent decrease is plotted against the measured NO emissions in Fig. 16. The apparent decrease due to dilution was obtained by normalizing the measured NO emission (with no dilution) by the ratio of the flow rate at a given case to the flow rate with no dilution.

The measured reduction in NO emission with decrease in oxygen concentration is much higher than that obtained by dilution, outlining that the reduction in NO emission is not only due to the added flow rate (dilution from the exhaust) but also due to the lower combustion temperature (as the diluents act as a heat sink) and different chemical kinetics at low oxygen concentrations.

\subsection{Oxygen Concentration and Recirculation Ratio}


The data showed a steep reduction in NO emission (50 70\%) with oxygen concentration reduced by only $3 \%$, down to $18 \%$ oxygen concentration in the fresh mixture at different diluent temperatures examined here. A further reduction in oxygen by $2 \%$ (to $16 \% \mathrm{O}_{2}$ ) resulted only in addition 15\% NO reduction indicating a diminishing return. If we decrease oxygen, if possible, by another $2 \%$ (to $14 \%$ ), NO emission is further reduced by about $8 \%$, leading to a total reduction of about $80 \%$ for phi=0.9, see Fig. 17 .

Similar trend was demonstrated at an equivalence ratio of 0.7. A three percent reduction in oxygen concentration leads to $60-75 \%$ reduction in NO emission, further reduction of $2 \%$ leads to addition decrease of about $20 \%$. Additional decrease in $\mathrm{O}_{2}$ concentration lead to unstable combustion for lower diluents temperature.

Oxygen concentration has a significant impact on the reaction distribution as seen through the $\mathrm{OH}^{*}$ chemiluminescence shown in Figs. 6, 9 and 14, which reflected on the change in NO emission. Each of the $\mathrm{OH}^{*}$ chemiluminescence image was analyzed to obtain the maximum, mean, and standard deviation and the results are shown in Fig. 18. The mean was normalized by the maximum of each image to indicate how close the mean is to the maximum signal (higher percentage indicates better signal distribution). Also, the standard deviation was normalized by the mean where a smaller percentage indicate that the intensity all over the image is closer to the mean value.

As the oxygen concentration is reduced, the ratio of the mean to the maximum increases significantly from about $10 \%$ (for normal air) up to $25 \%$ at $\mathrm{O}_{2}$ concentration of $14.5 \%$ (Phi=0.9). Lower equivalence ratio led to better distribution as well (12\% for $21 \% \mathrm{O}_{2}$ and $40 \%$ for $14.5 \%$ $\mathrm{O}_{2}$ ). Also, the standard deviation decreased significantly from $160 \%$ at $21 \% \mathrm{O}_{2}$, down to $\sim 80 \%$ at $14.5 \% \mathrm{O}_{2}$. The lower standard deviation indicates that the intensity values are closer to the 
mean value of the intensity. Increase in the heat load resulted in similar results for both the average to maximum ratio and the standard deviation to mean ratio. Injecting the diluents at a temperature of $600 \mathrm{~K}$ led to similar trend with better results for both ratio due to the extended operation at low oxygen concentration. At $11.24 \% \mathrm{O}_{2}$, the average to maximum was about $37 \%$ while the standard deviation to mean was about $45 \%$.

The obtained emission data can be used to derive a relation between NO emission and oxygen concentration in the fresh mixture. To better fit the data, a second degree polynomial fit was chosen. This relation is shown in Fig. 19 along with the different data points at an equivalence ratio of 0.9 for all the temperatures examined. This relation takes the following form:

$$
\mathrm{NO}[\mathrm{PPM}]=0.1317 *\left[\mathrm{O}_{2}\right]^{2}-3.1087 *\left[\mathrm{O}_{2}\right]+20.012
$$

Where, NO is in PPM corrected to $15 \% \mathrm{O}_{2}$, and $\mathrm{O}_{2}$ is the percent oxygen concentration. This relation had a regression coefficient of 0.9578 indicating a very good fit.

Similarly a relation can be obtained for the percent reduction in NO emission as compared to NO emission using air (21\% Oxygen). This relation takes the following form:

$$
\text { Reduction in NO emission }[\%]=-0.9905 *\left[\mathrm{O}_{2}\right]^{2}+23.373 *\left[\mathrm{O}_{2}\right]-50.462
$$

with a regression coefficient of 0.9578 .

Similar analysis at equivalence ratio of 0.7 revealed similar relations with a regression coefficient of 0.9655 .

$$
\begin{aligned}
& \mathrm{NO}[\mathrm{PPM}]=0.1483 *\left[\mathrm{O}_{2}\right]^{2}-4.3816 *\left[\mathrm{O}_{2}\right]+33.034 \\
& \text { Reduction in NO emission }[\%]=-2.2424 *\left[\mathrm{O}_{2}\right]^{2}+66.239 *\left[\mathrm{O}_{2}\right]-399.4
\end{aligned}
$$

Reduction of the oxygen concentration down to about $16 \%$ requires knowledge of the combustor operational equivalence ratio (dictating the amount of excess oxygen concentration in 
the recirculated hot gases inside the combustor). If the combustor is operated at an equivalence ratio of 0.6 (with $9 \% \mathrm{O}_{2}$ in the combustion exhaust without dilution), achieving an oxygen concentration of $16 \%$ will dictate a recirculation ratio of 0.7 (that is the amount of hot recirculated gases is equal to 0.7 of that of the fresh air intake) [21]. On the other hand, if the combustor is operated at an equivalence ratio of 0.9 , achieving oxygen concentration of $16 \%$ requires only a recirculation ratio of 0.35 . However, such high equivalence ratio result in higher emission and further recirculation is suggested to achieve emissions below 2 PPM. For this low emission level, a recirculation ratio of 0.9 is suggested (leading to oxygen concentration of $12 \%$ ). The increased amount of recirculating gases will increase the temperature prior to ignition, thus slightly increasing the emissions.

The knowledge of the required recirculation ratio to achieve $\mathrm{CDC}$ condition is extremely critical for combustor design. Based on this ratio, the flowfield can be better designed to ensure that enough amounts of gases are recirculated to form the required low oxygen concentration environment. As these gases are recirculated, enhanced mixing between the fresh reactants and recirculated gases from within the combustor is critical to ensure mixture uniformity for CDC conditions and ultra-low emissions.

\section{Conclusions}

Experiments were performed with different amount of nitrogen-carbon dioxide mixture added to the fresh air prior to combustion. This gas mixture was added to simulate the impact of internal recirculation of hot product gases from within the combustor to result in low oxygen concentration environment prior to ignition. 
Results obtained with different amount of oxygen concentration reduction in the fresh mixture led to significant decrease in $\mathrm{NO}$ emission with minimal impact on $\mathrm{CO}$ emission. $\mathrm{NO}$ emission was reduced by more than $60 \%$ and emissions lower than 4PPM were demonstrated regardless of the operational equivalence ratio (at oxygen concentration of 17\%). Lower NO emissions were also demonstrated with further reduction of $\mathrm{O}_{2}$ concentration.

$\mathrm{OH}^{*}$ chemiluminescence showed a significant reduction in signal intensity with oxygen concentration of $17 \%$ or lower, where the swirl structure disappears and a more distributed reaction takes over, with the mean $\mathrm{OH}^{*}$ signal being closer to the maximum signal and a much lower standard deviation across the combustor. This behavior agrees with the reduction of NO emission at these concentration for the equivalence ratio examined.

The experiments at higher heat load and thermal (heat) release intensity showed similar trends on NO reduction with minimal impact on $\mathrm{CO}$ emission. The reaction distribution, captured through $\mathrm{OH}^{*}$ chemiluminescence was significantly enhanced for oxygen concentration of $17 \%$ or lower.

Oxygen reduction by $3 \%$ (down to $18 \%$ ) resulted in about $60 \%$ reduction in $\mathrm{NO}$ emission, with $75 \%$ reduction in emission with further reduction in oxygen concentration by $2 \%$ (down to $16 \%$, outlining the significant impact of oxygen concentration on the behavior of the mixture and the resulting emissions. Relations describing the impact of oxygen concentration on NO emissions and the reduction in emission were derived, showing favorable agreement with data obtained for various temperatures of diluent mixture.

The obtained data suggests that, to foster CDC conditions, an oxygen concentration of $16 \%$ is favored in the fresh mixture. Such oxygen concentration will require a recirculation ratio of 0.7 if 
the combustor is to operate at an equivalence ratio of 0.6. Such knowledge is critical in the design of combustor flowfield to achieve the required recirculation ratio at the design points.

\section{Acknowledgments}

This research was supported by ONR and DoE. Their support is gratefully acknowledged. The support provided by Reaction Design is also gratefully acknowledged.

\section{References}

[1] Tsuji H, Gupta AK, Hasegawa T, Katsuki M, Kishimoto K, Morita M. High Temperature Air Combustion: From Energy Conservation To Pollution Reduction. Boca Raton, Florida: CRC Press; 2003.

[2] Arghode VK, and Gupta AK. Effect Of Flow Field For Colorless Distributed Combustion (CDC) For Gas Turbine Combustion. J. Applied Energy 2010;87:1631-1640.

[3] Khalil AEE, and Gupta AK. Swirling Distributed Combustion For Clean Energy Conversion In Gas Turbine Applications. J. Applied Energy, 2011:88:3685-3693.

[4] Khalil AEE, and Gupta AK. Distributed Swirl Combustion For Gas Turbine Application. J. Applied Energy, 2011;88:4898-4907.

[5] Khalil AEE, Gupta AK, Bryden MK, Lee SC. Mixture Preparation Effects on Distributed Combustion for Gas Turbine Applications. J. Energy Resour. Technol., 2012;134(3):032201.

[6] Correa SM. A Review of NOx Formation under Gas-Turbine Combustion Conditions. Combustion Science and Technology, 1992;87:329-362.

[7] Khalil AEE, and Gupta, AK. Fuel Flexible Distributed Combustion With Swirl For Gas Turbine Applications. J. Applied Energy, 2013;109:327-334. 
[8] Khalil AEE, and Gupta, AK. Velocity and Turbulence Effects on High Intensity Distributed Combustion. J. Applied Energy, 2014;125:1-9.

[9] Gupta AK. Thermal Characteristics of Gaseous Fuel Flames Using High Temperature Air. J. Eng. Gas Turbines Power, 2004;126(9):pp. 9-19.

[10] Kitagawa K, Konishi N, Arai N, and Gupta AK. Temporally Resolved 2-D Spectroscopic Study on the Effect of Highly Preheated and Low Oxygen Concentration Air on Combustion. J. Eng. Gas Turbines Power, 2003;125:326-331.

[11] ElKady AM, Evulet A, Brand A, Ursin TP, Lynghjem A. Exhaust Gas Recirculation in DLN F-Class Gas Turbines for Post-Combustion $\mathrm{CO}_{2}$ Capture. Proceedings of ASME Turbo Expo 2008: Power for Land, Sea and Air, GT2008, June 9-13, 2008, Berlin, Germany, Paper GT2008-51152.

[12] Evulet A, ElKady AM, Brand A, Chinn D. On the Performance and Operability of GE's Dry Low NOx Combustors utilizing Exhaust Gas Recirculation for Post-Combustion Carbon Capture. Energy Procedia, 2009;1:3809-3816.

[13] Nicol DG, Malte PC, Hamer AJ, Roby RJ, Steele RC. Development of a Five-Step Global Methane Oxidation-NO Formation Mechanism for Lean-Premixed Gas Turbine Combustion. J. Eng. Gas Turbines Power, 1999;121(2):272-280

[14] Li SC, and Williams FA. Reaction Mechanisms for Methane Ignition. . Eng. Gas Turbines Power, 2002;124:471-480.

[15] Al-Hamamre Z, Diezinger S, Talukdar P, Von Issendorff F, Trimis D. Combustion of low calorific gases from landfills and waste pyrolysis using porous medium burner technology. Process Safety Environ Protect, 2006;84(B4):297-308. 
[16] Stone R, Clarke A, Beckwith P. Correlations for the laminar-burning velocity of methane/diluent/air mixtures obtained in free-fall experiments. Combust Flame, 1998;114:54655.

[17] Galmiche B, Halter F, Foucher F, Dagaut P. Effects of Dilution on Laminar Burning Velocity of Premixed Methane/Air Flames. Energy \& Fuels, 2011;25:948-954

[18] Kim HS, Arghode VK, Linck MB, Gupta AK. Hydrogen Addition Effects in a Confined Swirl-Stabilized Methane-Air Flame. Int'l J. Hydrogen Energy, 2009;34(2):1054-1062.

[19] Kim HS, Arghode VK, Gupta AK. Flame Characteristics of Hydrogen-Enriched Methane-Air Premixed Swirling Flames. Int'1 J. Hydrogen Energy, 2009;34(2):1063-1073.

[20] Khalil AEE, and Gupta AK. Hydrogen Addition Effects on High Intensity Distributed Combustion. J. Applied Energy, 2013;104:71-78.

[21] Khalil AEE, and Gupta AK. Towards Distributed Combustion for Ultra-Low Emission Using Swirling and Non-Swirling Flowfields. J. Applied Energy, 2014;121:132-139. 


\section{Figure Captions}

Figure 1. Experimental test rig with flame using standard air (bottom right) and reduced oxygen concentrations (top right)

Figure 2. PSR temperature and NO emission variation with change in oxygen concentration of the fresh mixture at different dilution temperatures

Figure 3. Reduction in NO emission with change in oxygen concentration of the fresh mixture at different dilution temperatures

Figure 4. NO emission variation with change in oxygen concentration of the fresh mixture at different equivalence ratios

Figure 5. CO emission variation with change in oxygen concentration of the fresh mixture at different equivalence ratios

Figure 6. $\mathrm{OH}^{*}$ chemiluminescence intensity distribution for different equivalence ratio and oxygen concentration

Figure 7. NO emission variation with change in oxygen concentration at heat loads of $3.25 \mathrm{~kW}$ and $5 \mathrm{~kW}$

Figure 8. CO emission variation with change in oxygen concentration at heat loads of $3.25 \mathrm{~kW}$ and $5 \mathrm{~kW}$

Figure 9. $\mathrm{OH}^{*}$ chemiluminescence intensity distribution for different oxygen concentrations at heat load of $5 \mathrm{~kW}$

Figure 10. NO emission variation with change in oxygen concentration for heat release intensities of 2.4, 3.6, 5, and 7.78 $\mathrm{MW} / \mathrm{m}^{3}$-atm.

Figure 11. CO emission variation with change in oxygen concentration for heat release intensities of 2.4, 3.6, 5, and 7.78 $\mathrm{MW} / \mathrm{m}^{3}$-atm. 
Figure 12. NO emission variation with change in oxygen concentration for different $\mathrm{N}_{2}-\mathrm{CO}_{2}$ temperature

Figure 13. $\mathrm{CO}$ emission variation with change in oxygen concentration for different $\mathrm{N}_{2}-\mathrm{CO}_{2}$ temperature

Figure 14. $\mathrm{OH}^{*}$ chemiluminescence intensity distribution for different oxygen concentrations at diluents temperature of $600 \mathrm{~K}$

Figure 15. Change in flame visible emissions with increasing $\mathrm{N}_{2}-\mathrm{CO}_{2}$ amounts (reducing $\mathrm{O2}$ concentration) at diluents temperature of $600 \mathrm{~K}$

Figure 16. Comparison of measured NO emission (dashed line) to that obtained by accounting for dilution (solid line) for equivalence ratios of 0.9 and 0.7

Figure 17. Reduction in NO emission with change in oxygen concentration for the temperatures examined at equivalence ratios of 0.9 and 0.7

Figure 18. Mean $\mathrm{OH}^{*}$ (solid, normalized by maximum intensity) and standard deviation (dashed, normalized by mean) at different oxygen concentration cases for heat loads of $3.25 \mathrm{~kW}$ and $5 \mathrm{~kW}$, equivalence ratios of 0.9 and 0.7 , and diluents temperature of $300 \mathrm{~K}$ and $600 \mathrm{~K}$

Figure 19. NO emission and reduction in NO emission with change in oxygen concentration for the temperatures examined at equivalence ratio of 0.9

Table Captions

Table 1. Experimental parameters 


\section{Figures}



Figure 1. Experimental test rig with flame using standard air (bottom right) and reduced oxygen concentrations (top right) 
Figure 2

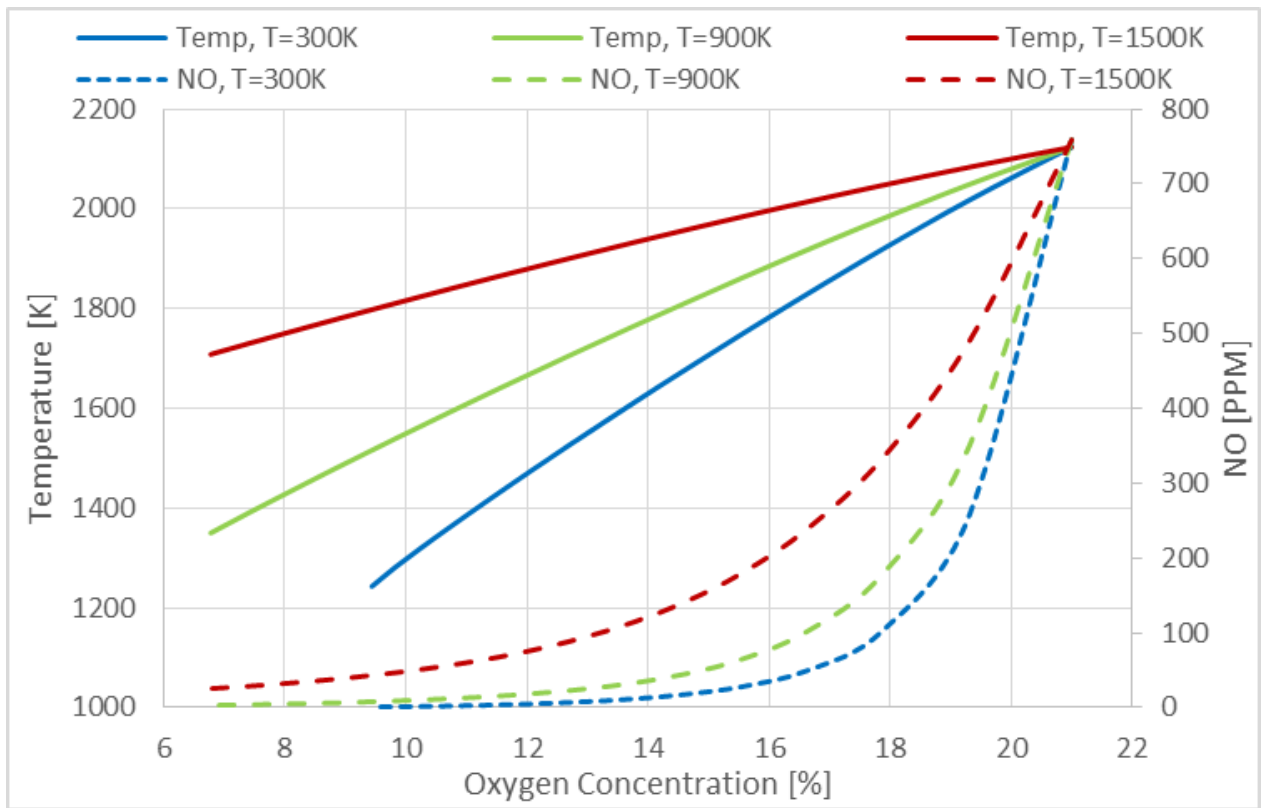

Figure 2. PSR temperature and NO emission variation with change in oxygen concentration of the fresh mixture at

different dilution temperatures 


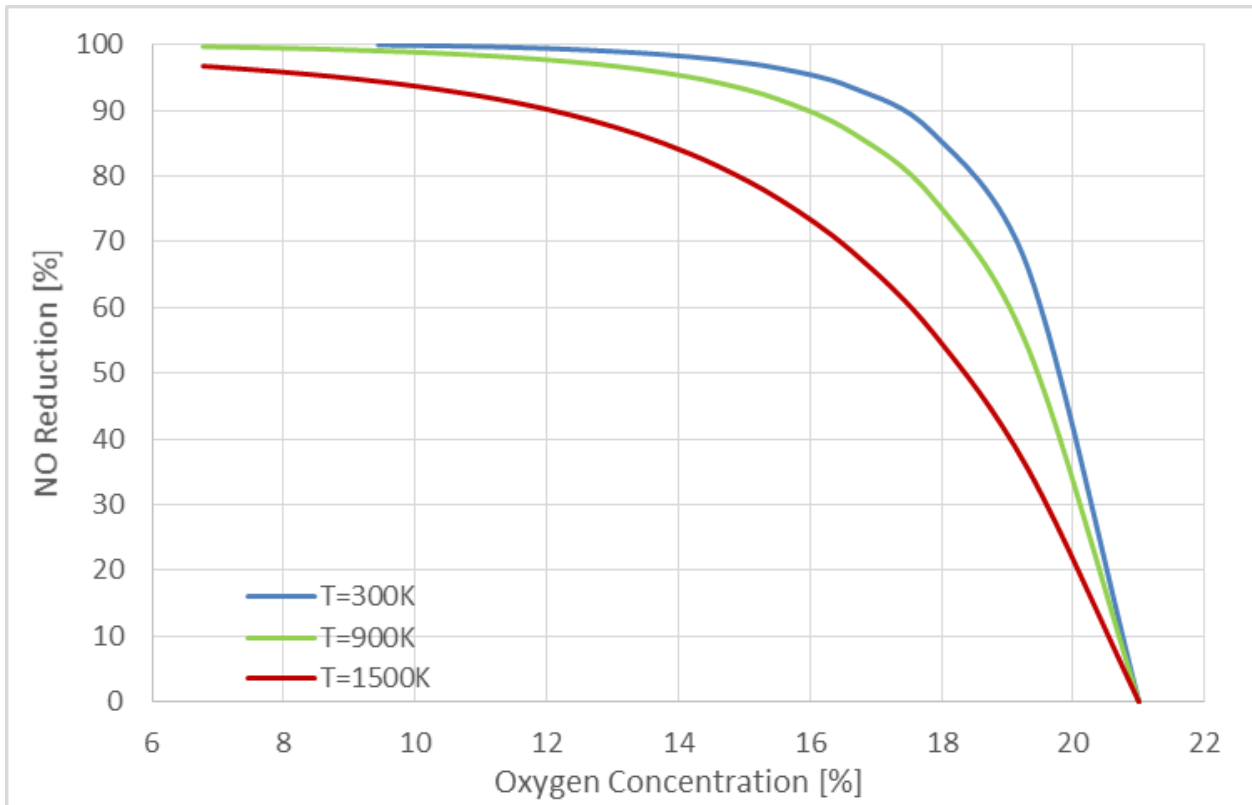

Figure 3. Reduction in NO emission with change in oxygen concentration of the fresh mixture at different dilution temperatures 


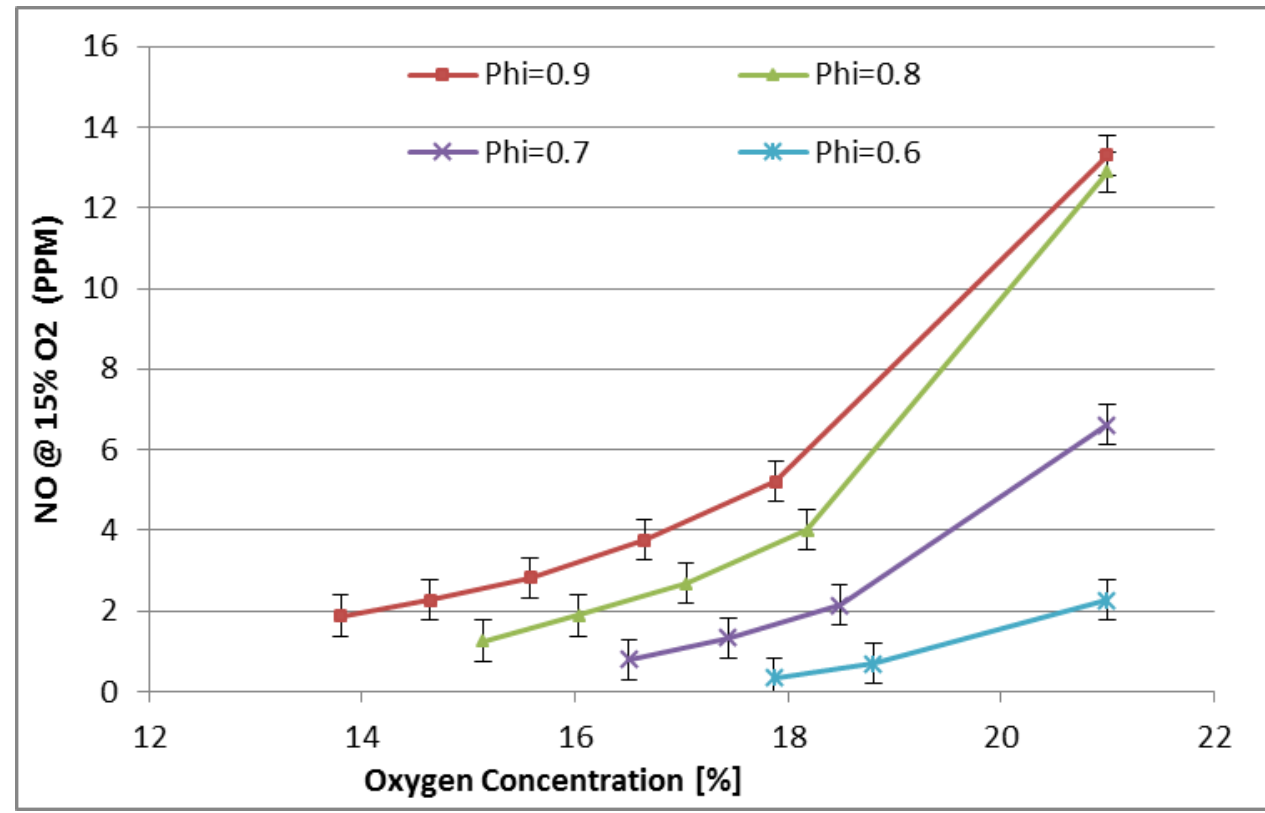

Figure 4. NO emission variation with change in oxygen concentration of the fresh mixture at different equivalence ratios 


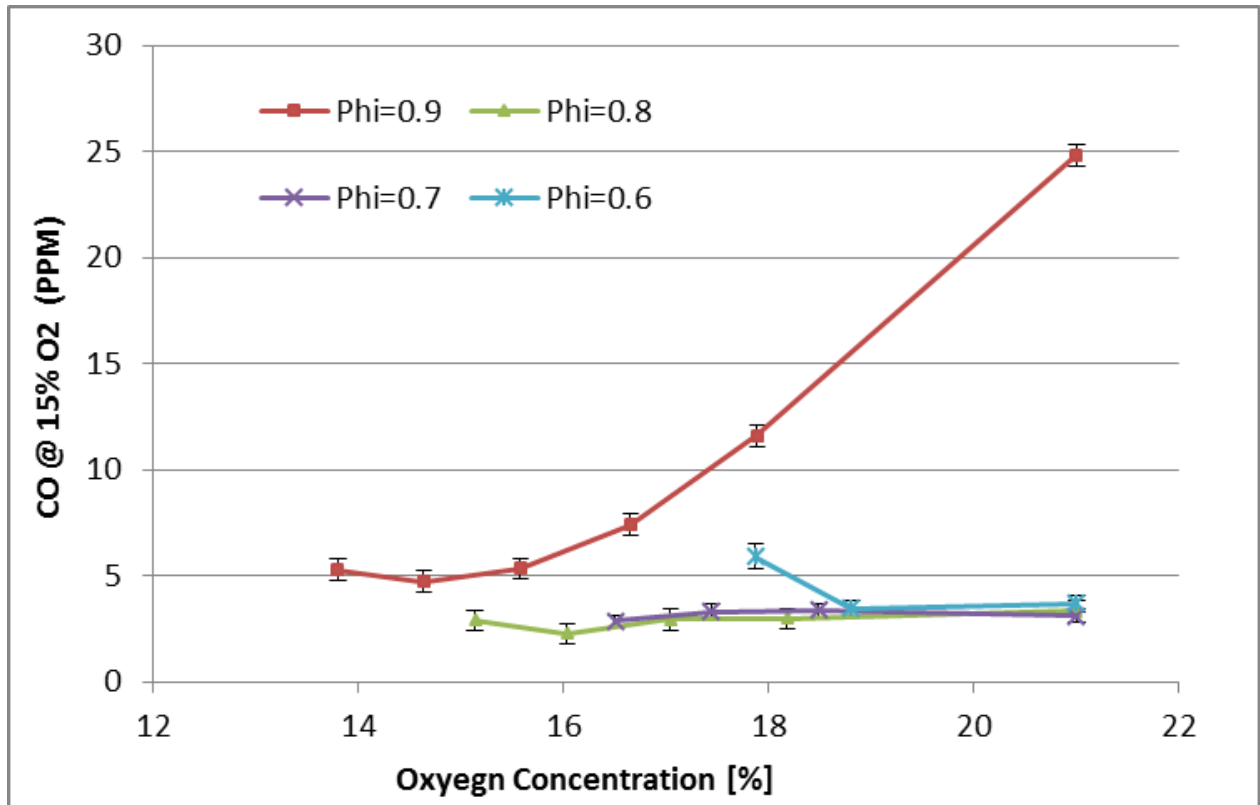

Figure 5. $\mathrm{CO}$ emission variation with change in oxygen concentration of the fresh mixture at different equivalence ratios 


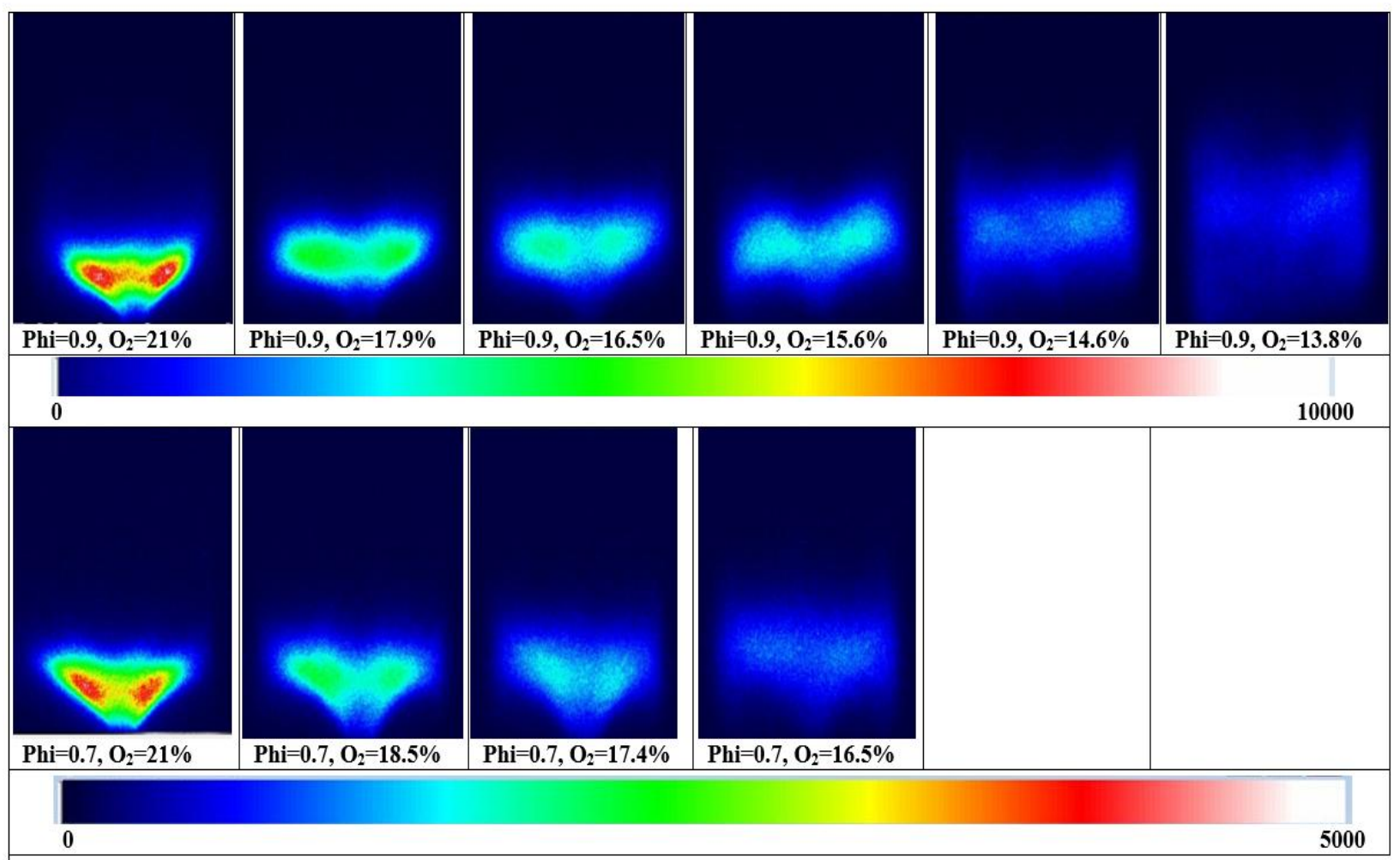

Figure $6 . \mathrm{OH}^{*}$ chemiluminescence intensity distribution for different equivalence ratio and oxygen concentration 


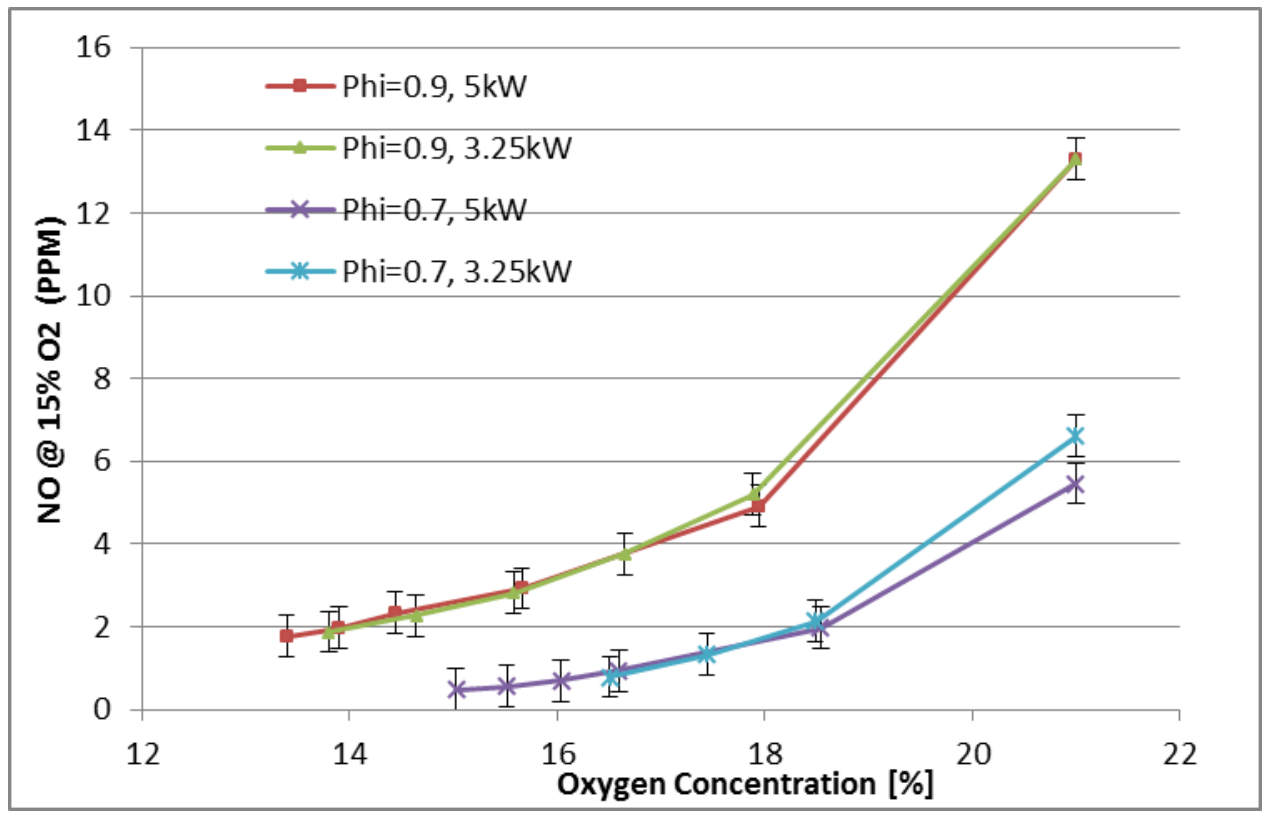

Figure 7. NO emission variation with change in oxygen concentration at heat loads of $3.25 \mathrm{~kW}$ and $5 \mathrm{~kW}$ 


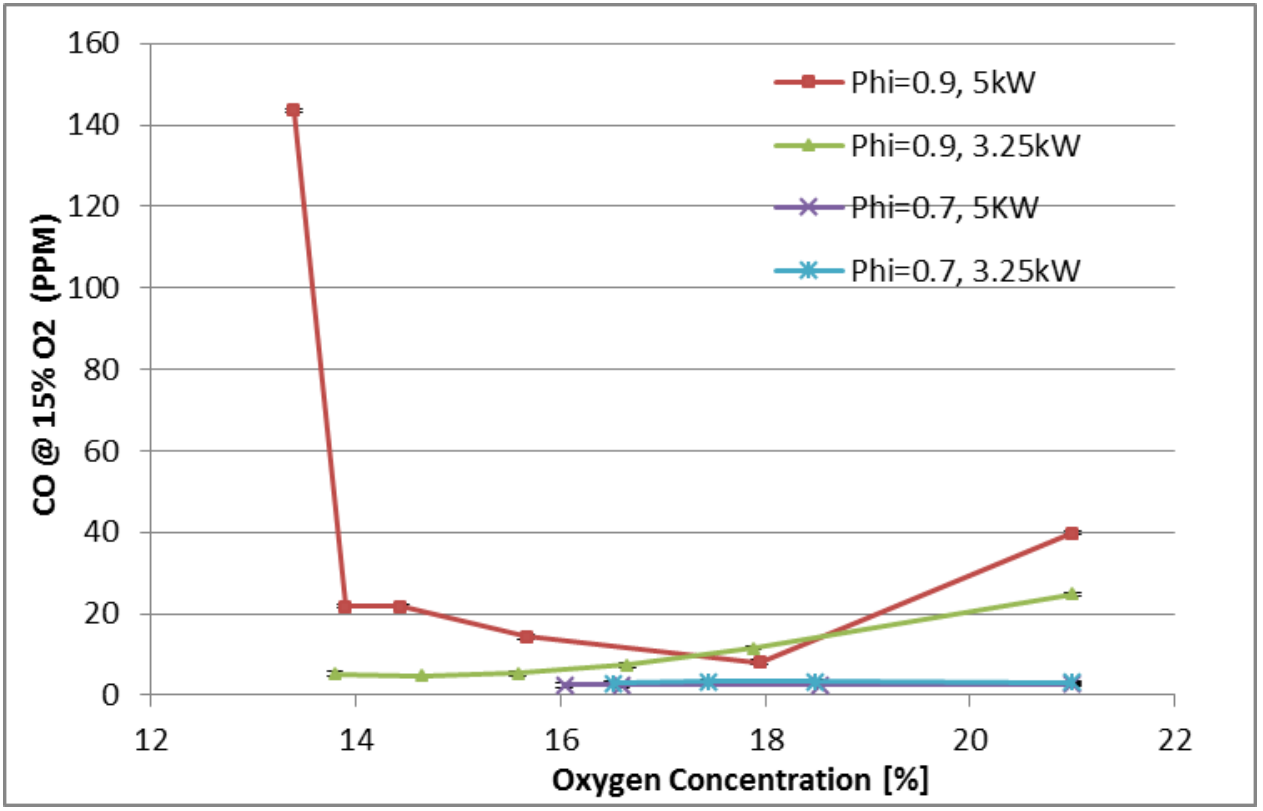

Figure 8. CO emission variation with change in oxygen concentration at heat loads of $3.25 \mathrm{~kW}$ and $5 \mathrm{~kW}$ 


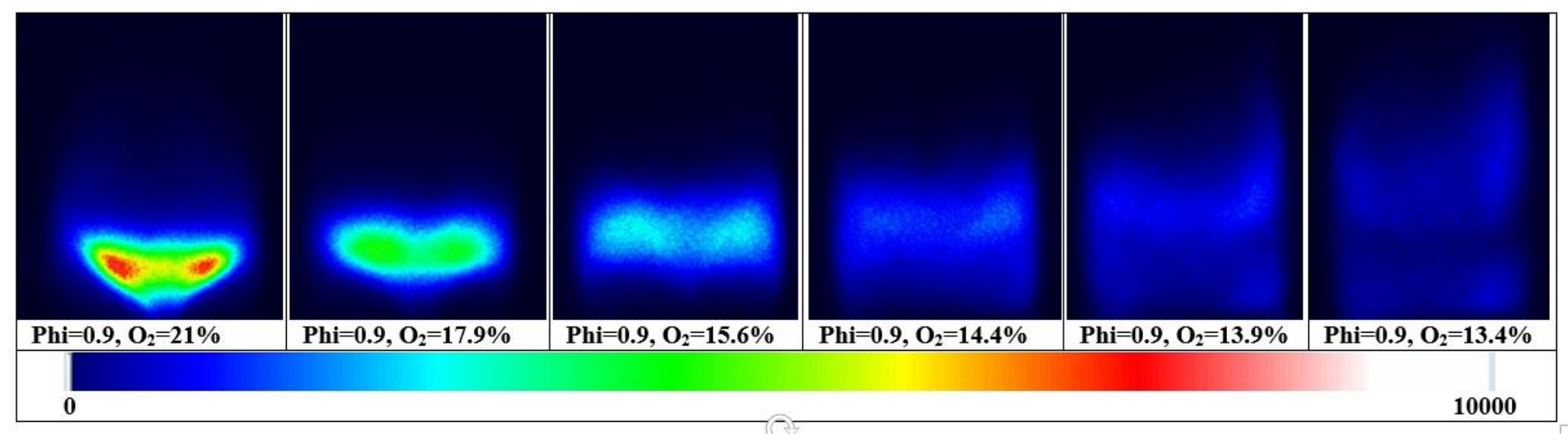

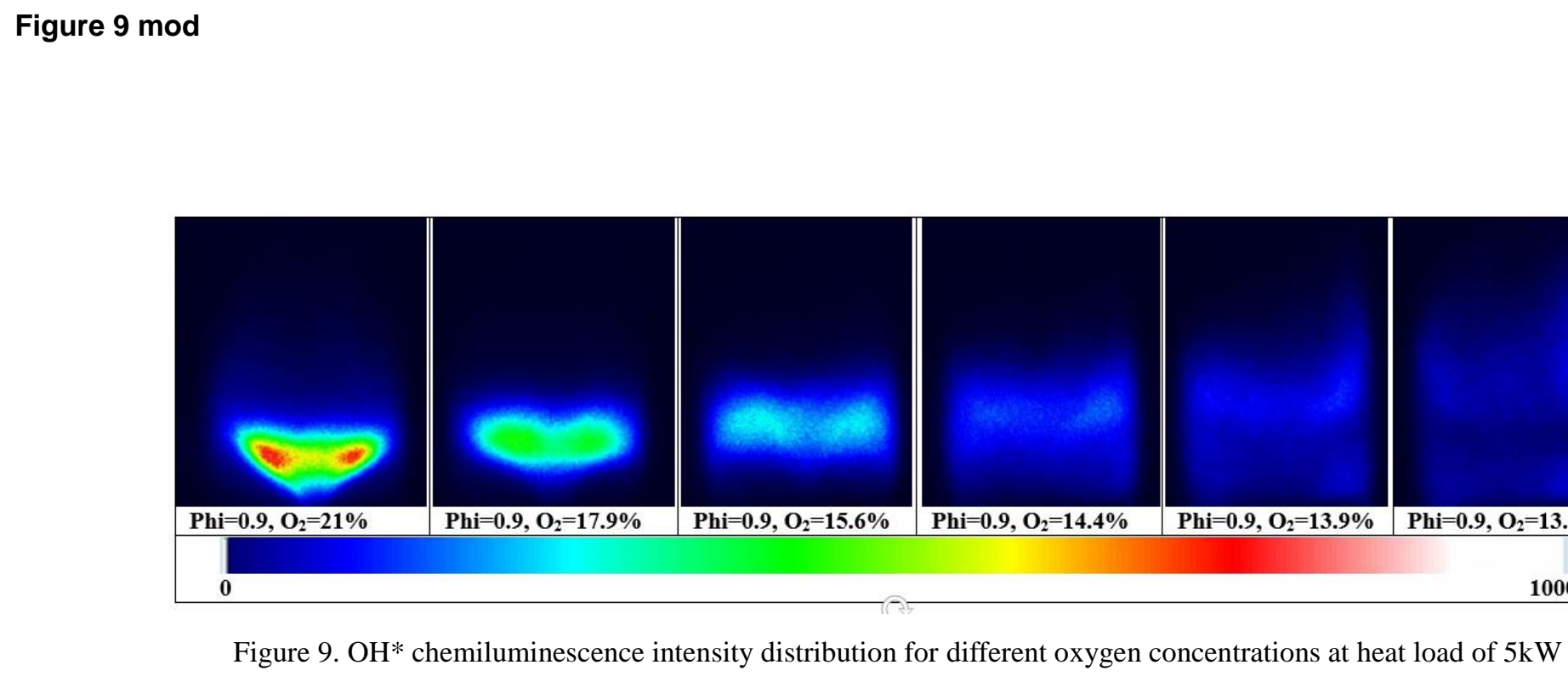

(a)

.

$\sqrt{3}$

(1)

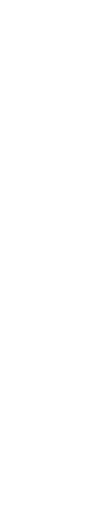




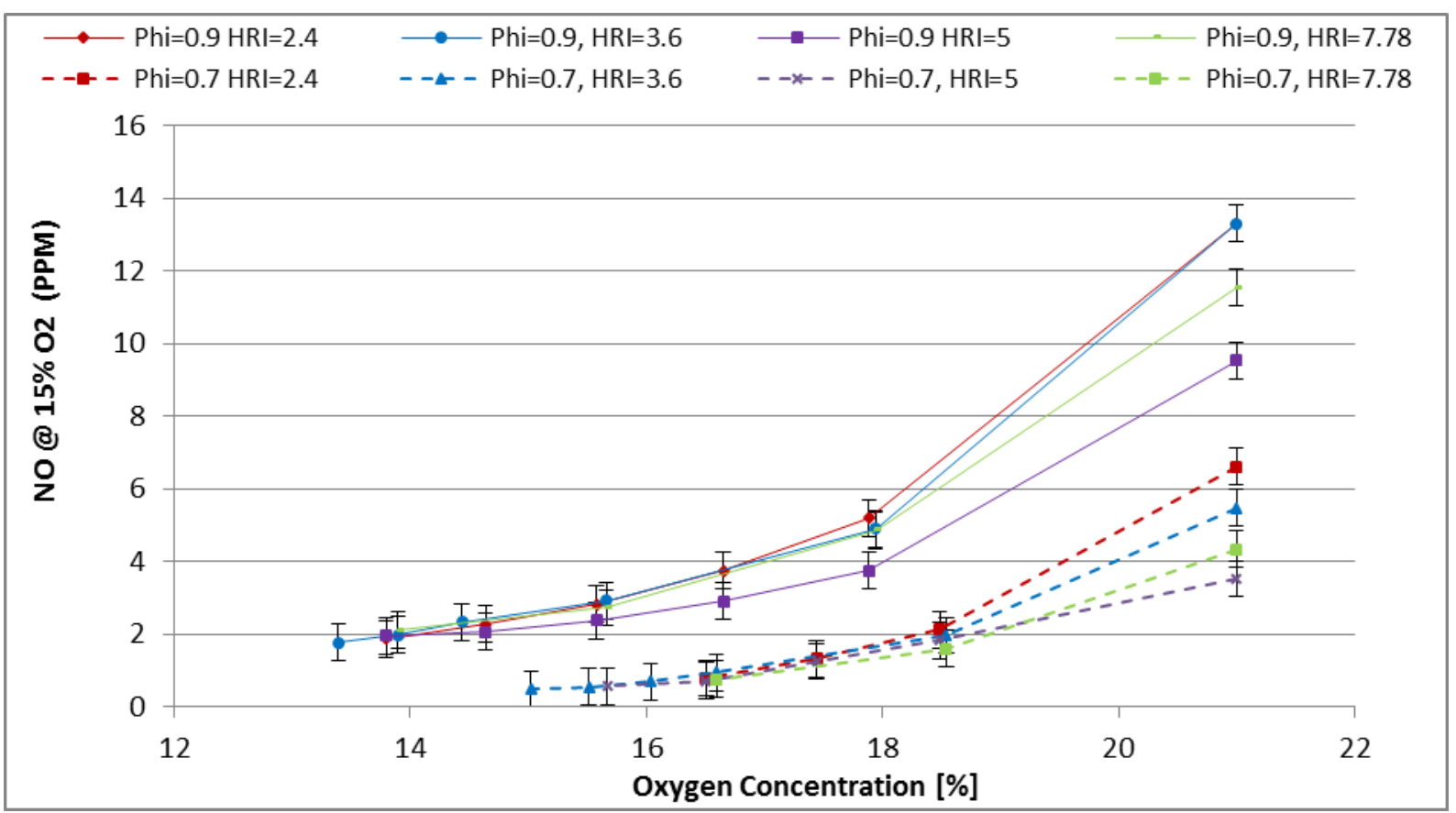

Figure 10. NO emission variation with change in oxygen concentration for heat release intensities of 2.4, 3.6, 5, and $7.78 \mathrm{MW} / \mathrm{m}^{3}$-atm. 


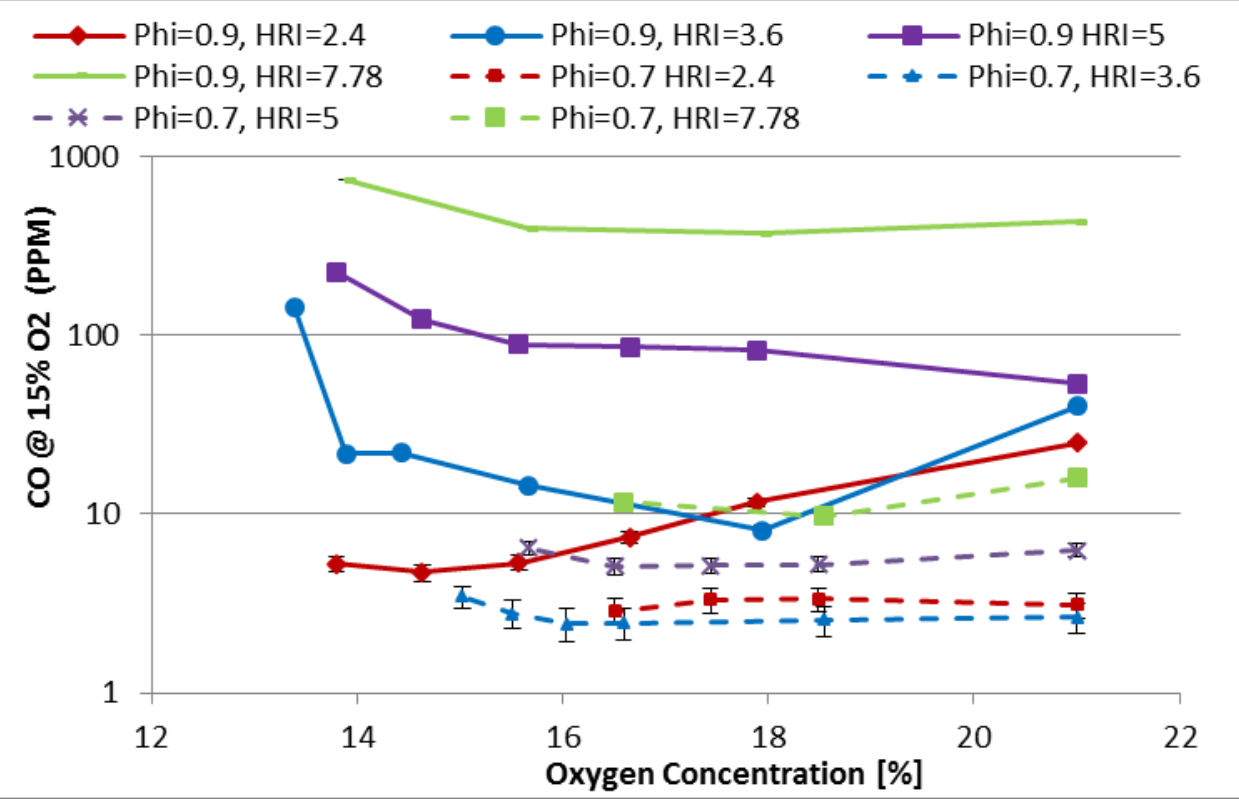

Figure 11. CO emission variation with change in oxygen concentration for heat release intensities of 2.4, 3.6, 5, and $7.78 \mathrm{MW} / \mathrm{m}^{3}$-atm. 


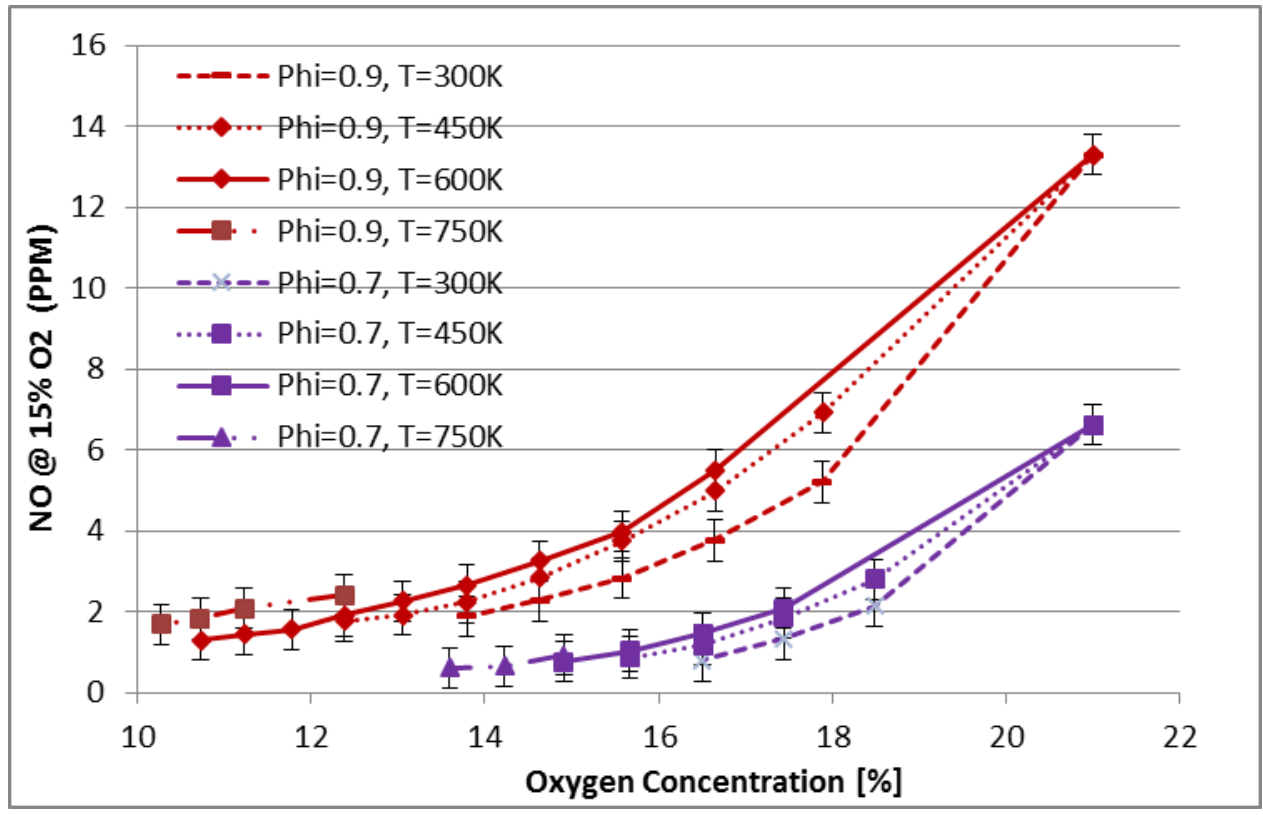

Figure 12. $\mathrm{NO}$ emission variation with change in oxygen concentration for different $\mathrm{N}_{2}-\mathrm{CO}_{2}$ temperature 


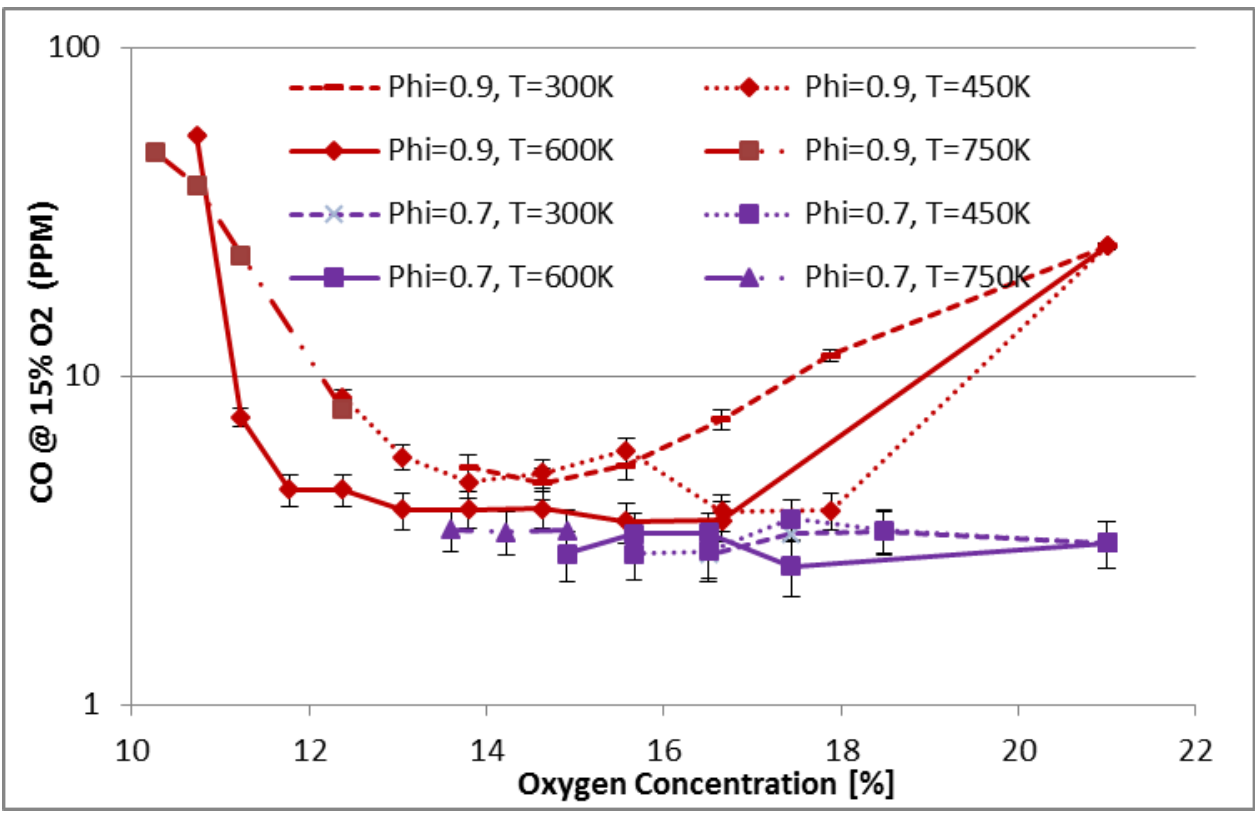

Figure 13. $\mathrm{CO}$ emission variation with change in oxygen concentration for different $\mathrm{N}_{2}-\mathrm{CO}_{2}$ temperature 


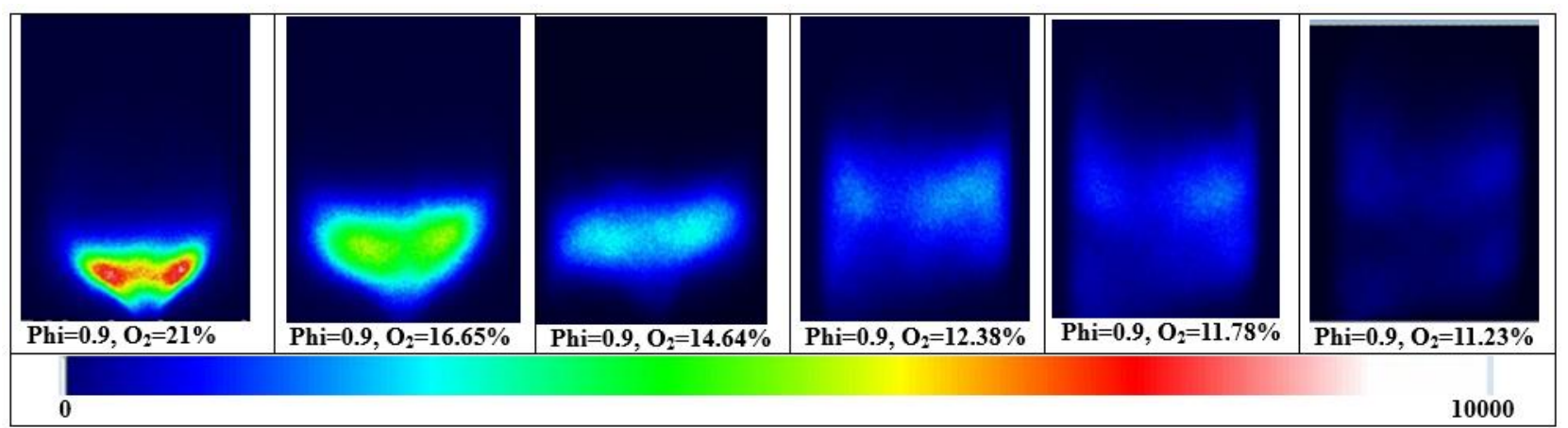

Figure $14 . \mathrm{OH}^{*}$ chemiluminescence intensity distribution for different oxygen concentrations at diluents temperature of $600 \mathrm{~K}$ 


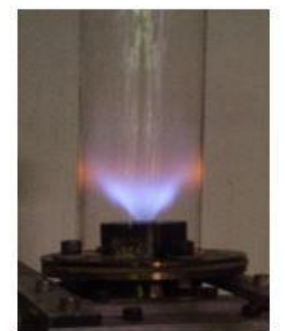

Phi $=0.9, \mathrm{O}_{2}=21 \%$



Phi $=0.9, \mathrm{O}_{2}=14.64 \%$


Figure 15. Change in flame visible emissions with increasing $\mathrm{N}_{2}-\mathrm{CO}_{2}$ amounts (reducing $\mathrm{O}_{2}$ concentration) at diluents temperature of $600 \mathrm{~K}$ 


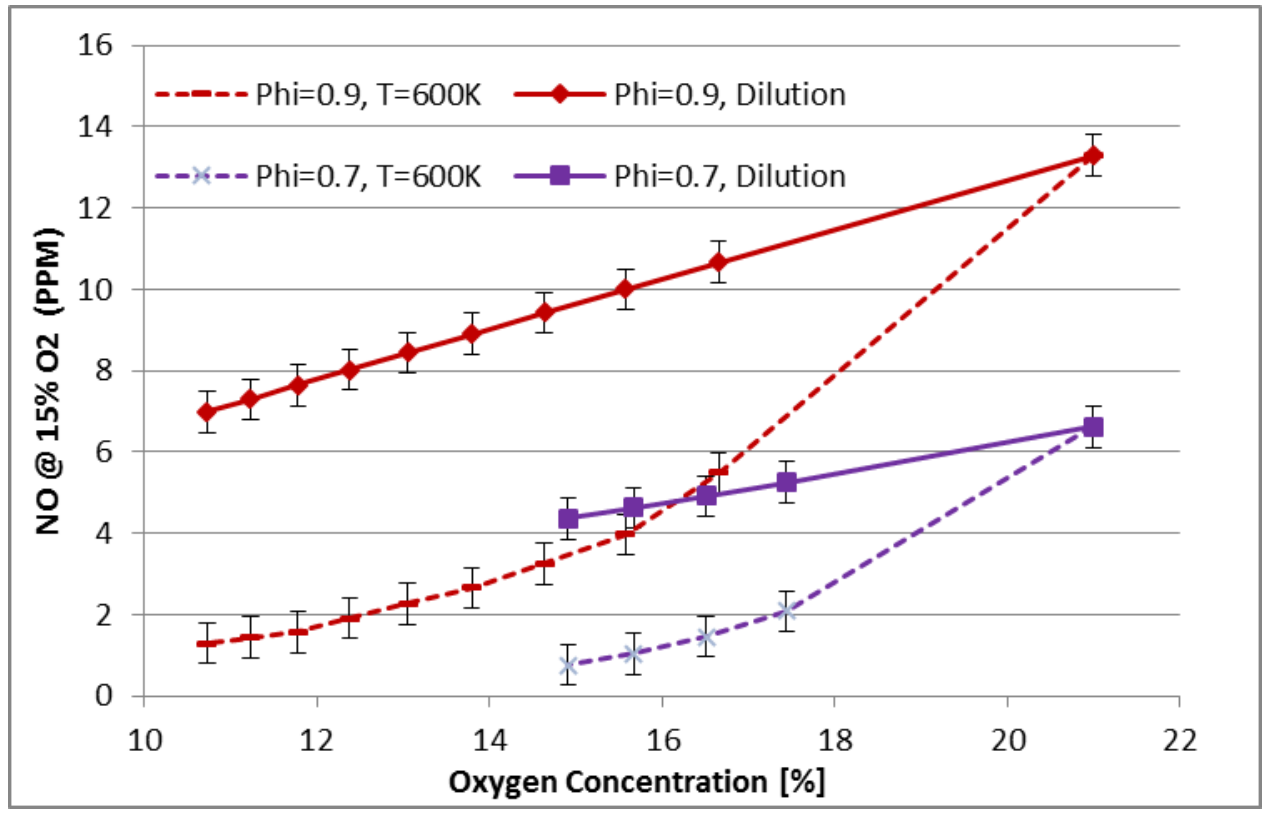

Figure 16. Comparison of measured NO emission (dashed line) to that obtained by accounting for dilution (solid line) for equivalence ratios of 0.9 and 0.7 


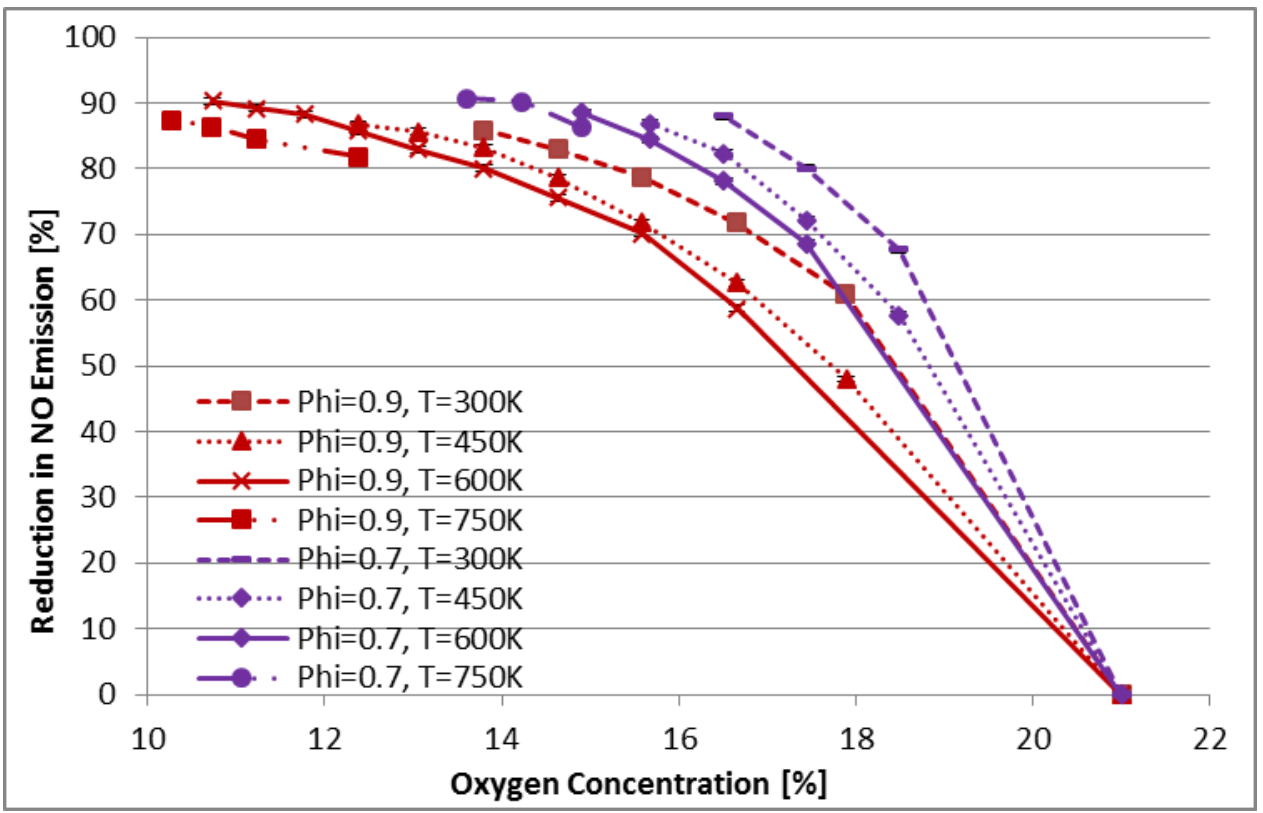

Figure 17. Reduction in NO emission with change in oxygen concentration for the temperatures examined at equivalence ratios of 0.9 and 0.7 




Figure 18. Mean $\mathrm{OH}^{*}$ (solid, normalized by maximum intensity) and standard deviation (dashed, normalized by mean) at different oxygen concentration cases for heat loads of $3.25 \mathrm{~kW}$ and $5 \mathrm{~kW}$, equivalence ratios of 0.9 and 0.7 , and diluents temperature of $300 \mathrm{~K}$ and $600 \mathrm{~K}$ 




Figure 19. NO emission and reduction in NO emission with change in oxygen concentration for the temperatures examined at equivalence ratio of 0.9 
TABL E

Table 1. Experimental parameters

\begin{tabular}{|c|c|c|c|c|}
\hline $\begin{array}{c}\text { Heat } \\
\text { Load }\end{array}$ & $\begin{array}{c}\text { Heat Release Intensity } \\
{\left[\mathbf{M W} / \mathbf{m}^{3} \text {-atm] }\right.}\end{array}$ & $\begin{array}{c}\text { Mixture } \\
\text { Temperature }\end{array}$ & $\begin{array}{c}\text { Equivalence } \\
\text { Ratio }\end{array}$ & $\begin{array}{c}\text { Oxygen } \\
\text { Concentration [\%] }\end{array}$ \\
\hline $3.25 \mathrm{~kW}$ & 2.4 & $300 \mathrm{~K}$ & 0.9 & $21-13.8$ \\
\hline $3.25 \mathrm{~kW}$ & 2.4 & $300 \mathrm{~K}$ & 0.8 & $21-15$ \\
\hline $3.25 \mathrm{~kW}$ & 2.4 & $300 \mathrm{~K}$ & 0.7 & $21-16.5$ \\
\hline $3.25 \mathrm{~kW}$ & 2.4 & $300 \mathrm{~K}$ & 0.6 & $21-17.8$ \\
\hline $5 \mathrm{~kW}$ & 3.6 & $300 \mathrm{~K}$ & 0.9 & $21-13.4$ \\
\hline $5 \mathrm{~kW}$ & 3.6 & $300 \mathrm{~K}$ & 0.8 & $21-14$ \\
\hline $5 \mathrm{~kW}$ & 3.6 & $300 \mathrm{~K}$ & 0.7 & $21-15$ \\
\hline $5 \mathrm{~kW}$ & 3.6 & $300 \mathrm{~K}$ & 0.6 & $21-17.6$ \\
\hline $3.25 \mathrm{~kW}$ & 5 & $300 \mathrm{~K}$ & 0.9 & $21-13.8$ \\
\hline $3.25 \mathrm{~kW}$ & 5 & $300 \mathrm{~K}$ & 0.8 & $21-15$ \\
\hline $3.25 \mathrm{~kW}$ & 5 & $300 \mathrm{~K}$ & 0.7 & $21-15.7$ \\
\hline $3.25 \mathrm{~kW}$ & 5 & $300 \mathrm{~K}$ & 0.6 & $21-17.9$ \\
\hline $5 \mathrm{~kW}$ & 7.78 & $300 \mathrm{~K}$ & 0.9 & $21-13.8$ \\
\hline $5 \mathrm{~kW}$ & 7.78 & $300 \mathrm{~K}$ & 0.7 & $21-16.6$ \\
\hline $3.25 \mathrm{~kW}$ & 2.4 & $450 \mathrm{~K}$ & 0.9 & $21-12.4$ \\
\hline $3.25 \mathrm{~kW}$ & 2.4 & $450 \mathrm{~K}$ & 0.8 & $21-14.3$ \\
\hline $3.25 \mathrm{~kW}$ & 2.4 & $450 \mathrm{~K}$ & 0.7 & $21-15.6$ \\
\hline $3.25 \mathrm{~kW}$ & 2.4 & $450 \mathrm{~K}$ & 0.6 & $21-17$ \\
\hline $3.25 \mathrm{~kW}$ & 2.4 & $600 \mathrm{~K}$ & 0.9 & $21-10.7$ \\
\hline $3.25 \mathrm{~kW}$ & 2.4 & $600 \mathrm{~K}$ & 0.7 & $21-14.9$ \\
\hline $3.25 \mathrm{~kW}$ & 2.4 & $750 \mathrm{~K}$ & 0.9 & $21-10.27$ \\
\hline $3.25 \mathrm{~kW}$ & 2.4 & $750 \mathrm{~K}$ & 0.7 & $21-13.6$ \\
\hline
\end{tabular}

